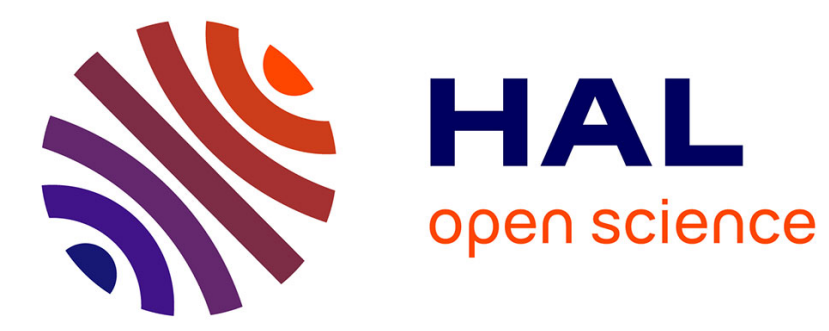

\title{
XAFS Study of the Main Constituent Elements of Layered Aluminosilicates
}

\author{
M. Castro, M. Alba, R. Alvero, A. Becerro, A. Muñoz-Páez, J. Trillo
}

\section{To cite this version:}

M. Castro, M. Alba, R. Alvero, A. Becerro, A. Muñoz-Páez, et al.. XAFS Study of the Main Constituent Elements of Layered Aluminosilicates. Journal de Physique IV Proceedings, 1997, 7 (C2), pp.C2-827-C2-828. 10.1051/jp4:1997250 . jpa-00255329

\section{HAL Id: jpa-00255329 https://hal.science/jpa-00255329}

Submitted on 1 Jan 1997

HAL is a multi-disciplinary open access archive for the deposit and dissemination of scientific research documents, whether they are published or not. The documents may come from teaching and research institutions in France or abroad, or from public or private research centers.
L'archive ouverte pluridisciplinaire HAL, est destinée au dépôt et à la diffusion de documents scientifiques de niveau recherche, publiés ou non, émanant des établissements d'enseignement et de recherche français ou étrangers, des laboratoires publics ou privés. 


\title{
XAFS Study of the Main Constituent Elements of Layered Aluminosilicates
}

\author{
M.A. Castro, M.D. Alba, R. Alvero, A.I. Becerro, A. Muñoz-Páez and J.M. Trillo \\ Departamento de Química Inorgánica, Instituto de Ciencia de Materiales, Universidad de Sevilla, CSIC, \\ P.O. Box 874, 41080 Sevilla, Spain
}

\begin{abstract}
Changes in the Si and Al $K$-edges XANES signals for a series of well characterized phyllosilicates have been examined. Results obtained for the different specimens have been interpreted in accordance with the changes in the structural compositions of the minerals and with the results of previous theoretical and experimental studies of related compounds. In both edges appear typical features that can be associated with dioctahedral and trioctabedral series.
\end{abstract}

\section{INTRODUCTION}

The atomic structures of common phyllosilicate minerals have been studied by numerous researchers for many years, from the generalizations of Pauling [1] for the structure of micas and related layer minerals. Essentially, 2:1 phyllosilicates consist of layers made up by condensation of a central octahedral sheet -composed of a closely packed oxygens or hydroxyls in which aluminium, iron, magnesium, or titanium atoms are embedded- which is sandwiched by two tetrahedral sheets. In these sheets $\mathrm{SiO}_{4}$ tetrahedra are linked with three neighbouring $\mathrm{SiO}_{4}$ tetrahedra, a hexagonal network being formed. 2:1 phyllosilicate minerals can be divided into two classes depending on their octahedral composition: trioctahedral minerals are formed when all the octahedral holes are occupied by bivalent cations and dioctahedral minerals occur when only two thirds of the available octahedral positions are occupied -in a neutral layer by means of trivalent cations-. This theoretical description yields electrically neutral layers. However, isomorphous substitutions in the tetrahedral sheet - $\mathrm{Al}$ and, occasionally, $\mathrm{Fe}$ for $\mathrm{Si}$ - or in the octahedral sheet confer a negative layer charge, which is balanced by cations, usually hydrated, located in the interlayer space.

Location of the layer charge as well as the distribution of isomorphous replacements determine both the structural stability and the physicochemical reactivity of these materials. Since the natural occurrence of these solids and the heterogeneity in the variety of them, these features are not easily understood and, in consequence, a large number of experimental techniques have been incorporated to the structural characterization of this family of compounds. Structural studies of these solids have used X-ray diffraction, X-ray emission spectroscopy, X-ray photoelectron spectroscopy, and magic-angle-spinning nuclear magnetic resonance spectroscopy measurements. Al and Si $K$-edge X-ray absorption spectroscopies have been applied to aluminosilicate minerals, a general overview of these measurements being recently published [2].

In this paper we present the results of a systematic study of well-characterized phyllosilicates by $\mathrm{Al}$ and Si $K$-edge X-ray absorption near-edge structure (XANES) spectroscopy. Appropriate selection of samples has allowed us to analyze the influence of the kind of material (tri- or dioctahedral), the coordination number of structural aluminium, and the amount of tetrahedral aluminium in the total composition. Moreover, the analysis of the spectra obtained from the different samples has permitted a comparison with the results recently published in the literature.

\section{EXPERIMENTAL METHODS}

Samples of representative species among 2:1 phyllosilicates have been selected including members of the dioctahedral and trioctahedral series with different tetrahedral aluminium contents and with different layer charge deficits, ranging from smectites to vermiculites. Structural formulae, characterization references and source repositories have been included in Table 1.

$\mathrm{X}$-ray absorption spectra of $\mathrm{Si}-\mathrm{K}$ and Al-K edges (at 1839 and $1562 \mathrm{eV}$ respectively) were recorded at the soft X-ray XAFS Station 3.4 from the SRS at Daresbury Laboratories (U.K.). The storage ring was operated at $\mathbf{2 . 0}$ $\mathrm{GeV}$ with a maximum stored current of $250 \mathrm{~mA}$. The Station 3.4 operates with double crystal monochromators InSb [111] and quartz [111] in the Si-K and Al-K edges, respectively. Higher harmonics contamination of the beam is small in these energies due to the use of collimating mirrors. The estimated resolution is better than $1.0 \mathrm{eV}$ for $\mathrm{Si}-\mathrm{K}$ edge and than $1.5 \mathrm{eV}$ for $\mathrm{Al}-\mathrm{K}$ edge. Data were collected in the total electron yield mode by recording the drain current. Steps of $0.25 \mathrm{eV}$ for the edge region and $1.0 \mathrm{eV}$ for the preedge and EXAFS region were selected, respectively. Two to four scans were averaged to minimize high and low frequency noise. The samples were mixed with graphite and mounted with epoxy resin onto aluminium or stainless steel sample holders to measure Si and AI K edges, respectively. XAFS measurements were carried out under vacuum $\left(\sim 10^{-5}\right.$ Torr $)$ at room temperature.
Table 1. Structural Formulae of Phyllosilicates

\begin{tabular}{|c|c|c|c|c|c|c|c|c|c|}
\hline & SI & & Fe & & Te & & & & \\
\hline Trancos & 7.64 & 0.36 & & 3.06 & 0.27 & 0.69 & & & 0.87 \\
\hline$S W y 2^{\prime}$ & 7.86 & 0.14 & & 2.73 & 0.46 & 0.69 & & & 1.20 \\
\hline$S A z-1^{1}$ & 7.97 & 0.03 & & 2.71 & 0.14 & 1.13 & 0.02 & & 1.12 \\
\hline SBCa+1 $1^{2}$ & 7.13 & 0.87 & & 3.91 & 0.04 & 0.05 & & & 0.92 \\
\hline $\mathrm{SHCa}^{3} \mathrm{1}^{3}$ & 7.96 & 0.04 & & & & 5.30 & & 0.7 & 0.74 \\
\hline SapCa-14 & 6.85 & 1.15 & & 0.12 & 0.07 & 5.79 & & & 1.00 \\
\hline Palaboras & 5.81 & 1.80 & 0.39 & & 0.47 & 5.28 & 0.24 & & 1.71 \\
\hline Eucatex ${ }^{5}$ & 6.22 & 1.78 & & 0.05 & 0.61 & 5.05 & 0.08 & & 1.40 \\
\hline
\end{tabular}

'montmorillonite; ${ }^{2}$ beidellite; ${ }^{3}$ hectorite; ${ }^{4}$ saponite; ${ }^{5}$ vermiculite 


\section{RESULTS AND DISCUSSION 3.1 Si $K$-edge XANES spectra}

Figure 1 shows Si $K$-edge XANES spectra for the different layered silicates studied. All of them yield an intense white line ( $C$ feature) related to tetrahedral coordination and several resonances (D and $E$ features) at higher energies. The main peak, peak $C$, is assigned to the transition of $\mathrm{Si} 1 s$ electrons to the antibonding $3 p$-like state $\left(\mathrm{t}_{2}\right)$. The energy position of this peak is determined by the polymerization of $\mathrm{SiO}_{4}^{4-}$ clusters, the substitution of $\mathrm{Al}$ for $\mathrm{Si}$ in the tetrahedral sheet, and the substitution of $\mathrm{Al}$ for $\mathrm{Mg}$ in octahedral sites and it has been examined in a wide range of natural silicates [2]. As all the samples measured in the present study correspond to $Q^{3}$ environments and as the shifts reported in the literature are only of the order of $0.1 \mathrm{eV}$, lower than the resolution employed by us, no changes are oberved for the $C$ peak position for all the samples except in the case of Palabora vermiculite, which exhibits the highest content in tetrahedral Al and in layer deficit charge.

The post-edge features clearly contain important information on the structure and bonding of silicates although they are complicated owed to multiple scattering effects. This part of the spectrum is the most variable for our samples and provide information on their local structures. Firstly, peak $E$ is shifted from dioctahedral to trioctahedral silicates. In trioctahedral silicates $d_{\text {si- }}$ is longer than in dioctahedral silicates, and this can explain, in accordance with the studies performed by Natoli [3] the shift of the feature E towards lower energy for trioctahedral samples. Moreover this peak is more pronounced in the latter silicates and this can be owed to the complete occupancy of their octahedral sheet that produces a bigger coherence of multiple scattering in these samples [4]. Secondly, peak $D$ appears clearly in all the dioctahedral samples but only in one of the trioctahedral minerals (Palabora vermiculite). Some controversy concerning this peak still exists because it cannot be attributed, in phyllosilicates, to the dioctahedral series and cannot either be explained on the basis of the existence of longer range order [4] because crystalline samples such as hectorite and saponite do not present it.

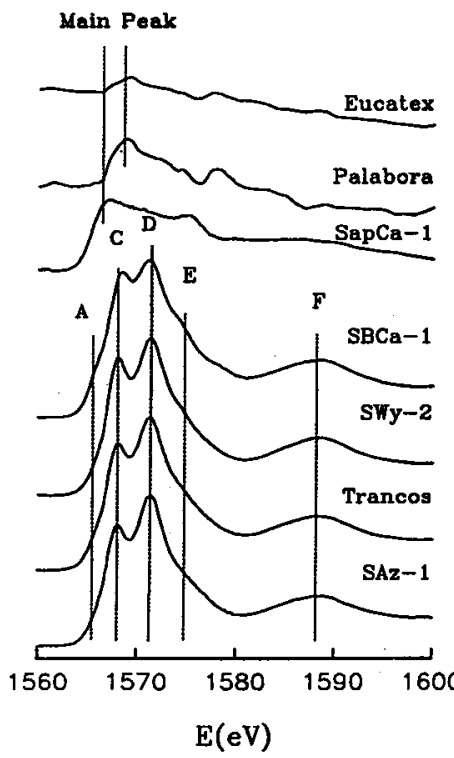

Figure 2 Al $K$-edge XANES spectra for the indicated samples

\subsection{Al $K$-edge XANES spectra}

Figure 2 includes the Al $K$-edge XANES spectra of the set of samples studied. Two different types of profiles are observable depending on the kind of the mineral, dioctahedral or trioctahedral, specimens from each group exhibiting a very similar pattern. The main peak of spectra corresponding to trioctahedral samples consists of a singlet centred at low energy values, while the white line of spectra shown by dioctahedral minerals is composed by a doublet located at higher energy values. The general appearance of both types is completed with a set of shoulders lying at both sides of the white line, whose have been marked and denoted in the Figure in accordance with previous reports [2].

Absolute intensities for the trioctahedral samples are lower than those observed for the dioctahedral series, in accordance with the lower content in structural aluminium, only the main line being clearly observed. In general, profiles for these minerals resemble the $\mathrm{Si} K$-edge spectra obtained for the same minerals. This similarity can be due to the fact that they occupy equivalent sites in the crystalline structure. The peak positions, measured at the peak maximum, for the trioctahedral series are compatible with the distribution of values observed by $\mathrm{Li}$ et al. [2] for other tetrahedral aluminium-containing minerals, samples with a higher layer charge, vermiculites, showing higher energy values.

Regarding the spectra recorded for the dioctahedral series, peak $D$ appears at 1572 $\mathrm{eV}$ and is prominent for all the samples studied, peak $\mathrm{C}$ intensity being lower in all the cases, in contrast with the results reported by $\mathrm{Li}$ et al. [2]. Finally, although very similar profiles are obtained for all the samples, some slight changes are observed which become bigger as the ${ }^{\mathrm{IV}} \mathrm{Al}$ content increases: a) $\mathrm{A}$ and $\mathrm{E}$ peak intensities and $\mathrm{C}$ peak intensity to $\mathrm{D}$ peak intensity ratios are intensified, and $b$ ) $F$ peak position shifts to lower energy values.

\section{References}

[1]. Pauling,L., Prac.Natl.Acad.Sci.U.S. 16 (1930) 123-129.

[2]. Li D., Bancroft G.M., Fleet M.E., Feng X.H., Pan Y., Am.Mineral. 80 (1995) 432-440. Li D., Bancroft G.M., Fleet M.E., Feng X.H., Phys.Chem.Minerals 22 (1995) 115-122.

[3]. Natoli C.R., EXAFS and Near Edge Structure.A. Bianconi, L. Incoccia Eds. (Springer Series on Chem. Phys., 1983) 27 p.43.

[4]. Li D., Bancroft G.M., Kasrai M., Fleet M.E., Secco R.A., Feng X.H., Tan K.H., Yang B.X., Am. Mineral. 79 (1994) $622-632$. 